\title{
Abordaje de la parálisis de Bell: diagnóstico y tratamiento
}

\author{
Approach to Bell's paralysis: diagnosis and treatment
}

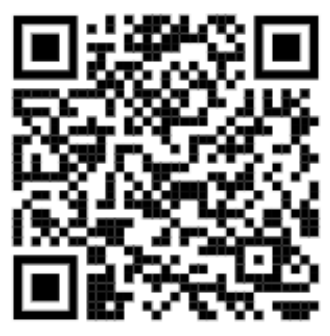

${ }^{1}$ Médico general, graduada de la Universidad de Ciencias Médicas (UCIMED), código médico:15214

ishtar-8@hotmail.com

${ }^{2}$ Médico general, graduado de la Universidad de Ciencias Médicas (UCIMED), código médico 15388 davidvb77@gmail.com

${ }^{3}$ Médico general, graduada de la Universidad San Judas Tadeo, código médico: 15613 caritobp22@gmail.com

\author{
${ }^{1}$ Dra. Ishtar Estefanía Saborío Cervantes \\ Investigadora Independiente, Heredia, Costa Rica \\ (D) https://orcid.org/0000-0002-0106-9953 \\ ${ }^{2}$ Dr. David Villalobos Bonilla \\ Instituto Nacional de Seguros (INS), San José, Costa Rica \\ (D) https://orcid.org/0000-0002-5369-8663 \\ ${ }^{3}$ Dra. Carolina Bolaños Parajeles \\ Hospital México, San José. Costa Rica \\ https://orcid.org/0000-0002-7749-7268 \\ RECIBIDO \\ CORREGIDO \\ ACEPTADO \\ 07/04/2019 \\ $20 / 04 / 2019$ \\ $02 / 05 / 2019$
}

\section{RESUMEN}

La parálisis de Bell o parálisis facial periférica es una enfermedad neuromuscular con afectación directa en el nervio facial. Es una patología común con un pico de presentación de los 20 a 29 años y los 50 a 59 años. Es de carácter idiopático, siendo la etiología provocada por el virus herpes simple la mayor sospecha causal. Se muestra como una parálisis facial unilateral súbita con empeoramiento posterior. Presenta sintomatología de afectación nerviosa muscular y sensitiva como dificultad para elevar la ceja, cerrar los ojos, sonreír, fruncir el ceño, parestesias faciales, hiperacusia, entre otros. Su diagnóstico principalmente es clínico, pero también se utilizan otros métodos diagnósticos complementarios para descartar diversas patologías. Es necesario un manejo pronto y oportuno para lograr la remisión completa y evitar complicaciones, este incluye corticoesteroides orales, valorar la utilización de antivirales y una adecuada protección ocular. La mayoría de los pacientes manifiestan remisión espontánea con una recuperación completa, los que muestran una recuperación incompleta pueden verse beneficiados de terapias físicas para mejorar la función facial y la prevención de secuelas como hipertonicidad, asimetría facial y sincinesias.

PALABRAS CLAVE: parálisis de Bell; nervio facial; herpes simple; corticoesteroides; antivirales. 


\begin{abstract}
Bell's palsy or peripheral facial paralysis is a neuromuscular disease with direct involvement of the facial nerve. It is a common pathology with presentation peaks at 20 to 29 years and 50 to 59 years. Although it is idiopathic, the herpes simplex virus is the main cause of suspicion. It is shown as a sudden unilateral facial paralysis with subsequent worsening. It presents symptoms such as muscular and sensitive nervous affectation like difficulty to raise the eyebrow, to close the eyes, to smile, to frown, facial paresthesias, hyperacusis, among others. Its diagnosis is mainly clinical, but other complementary diagnostic methods are also used to rule out various pathologies. It is necessary a prompt and timely management to achieve complete remission and avoid complications, this includes oral corticosteroids, assess the use of antivirals and an adequate eye protection. Most patients manifest spontaneous remission with a complete recovery, those who show an incomplete recovery can benefit from physical therapies to improve facial function and the prevention of sequelae such as hypertonicity, facial asymmetry and synkinesis.
\end{abstract}

KEYWORDS: Bell palsy; facial nerve; herpes simplex; corticosteroids; antiviral agents.

\section{INTRODUCCIÓN}

La parálisis de Bell data del siglo $\mathrm{V}$ a.C. inicialmente observada por el médico griego Hipócrates, posteriormente fue descrita por Sir Charles Bell en 1821, en donde detalla la anatomía del nervio facial y su asociación con una parálisis facial de causa idiopática (1). Esta patología se caracteriza por una parálisis facial unilateral súbita, al mismo tiempo que se expresa con una sintomatología de afectación motora y sensitiva. Al ser un cuadro neurológico se debe hacer un diagnóstico de exclusión de otras patologías de este tipo. La parálisis facial periférica se puede manifestar de forma parcial o completa y cursa en la mayoría de los casos con una recuperación completa. Puede presentarse en mujeres y hombres en una prevalencia similar. A pesar de ser un síndrome común, con necesidad de manejo precoz para mejorar o prevenir secuelas, su diagnóstico y tratamiento sigue siendo un reto para el médico. El objetivo de este artículo es brindarle al médico información actualizada sobre la parálisis de Bell, esto considerando la necesidad de un diagnóstico y tratamiento certero y temprano y de esta manera realizar un abordaje oportuno lo que llevaría finalmente a prevenir posibles complicaciones. Para esto se lleva a cabo una revisión bibliográfica de artículos científicos publicados del año 2014 en adelante, que incluyen la definición, etiología, manifestaciones clínicas, diagnóstico y tratamiento de esta frecuente patología.

\section{DEFINICIÓN}

La parálisis de Bell es un síndrome clínico neuromuscular habitual con 
afectación parcial o total del nervio facial también conocido como séptimo par craneal, se manifiesta como una parálisis facial periférica unilateral súbita (2).

\section{EPIDEMIOLOGÍA}

La parálisis de Bell es de origen idiopático, sin embargo, estudios científicos han identificado diversas causas con posible relación como lo es la reactivación del virus herpes simple y varicela zóster $(1,2,3)$. Esta afectación facial puede ser izquierda o derecha con el mismo porcentaje de incidencia (4). Elementos externos, por ejemplo, la época climática fría llegaría a ejercer una influencia en el incremento de más casos de esta patología, específicamente aquí corresponde a los cambios bruscos de temperatura $(5,6)$. Es una patología común con una incidencia global de 15 a 40 casos por cada 100.000 habitantes por año, con una afectación mundial anual de 40.000 individuos $(5,7)$. Su aparición es más frecuente en edades de los 20 a 29 años y 50 a 59 años, siendo inusual antes de los 6 años y después de los 60 años $(5,8)$.

Las mujeres en edad reproductiva presentan un leve aumento de casos en comparación con los varones, sin diferencia en los demás rangos de edad (9).

Además, existe un riesgo triplicado que se manifieste durante el periodo gestacional principalmente en el tercer trimestre de embarazo y en el postparto inmediato y mediato. Adicionalmente, los pacientes diabéticos, hipertensos e inmunodeficientes tienen un riesgo mayor de sufrir esta patología y al padecerla el $10 \%$ sufren recidivas $(2,10)$.

\section{ETIOLOGÍA}

De manera frecuente se denomina parálisis de Bell a la enfermedad caracterizada por una parálisis facial periférica aguda unilateral idiopática siendo un enigma su etiología específica $(2,7,11)$. Aun así, existe un gran número de estudios científicos que involucran mecanismos inmunitarios, infecciosos e isquémicos del nervio facial como causas potenciales para desarrollar la parálisis de Bell $(1,12)$.

Una de las posibles causas se encuentra en la infección por el virus del herpes simple reactivado (VHS-1), la cual constituye la etiología generalmente más aceptada, su fisiopatología está centrada alrededor de la afectación del ganglio geniculado y su capacidad neurotrópica para los nervios periféricos (6).

Dicha capacidad también se comparte por parte de otros virus como lo son el virus herpes simple tipo 2 (HSV-2) y el virus varicela zóster (VZV) los cuales entran en el cuerpo a través de la exposición mucocutánea, con afinidad por los nervios periféricos y establecen su presencia en forma latente $(1,6)$.

El virus del herpes zóster es la segunda infección viral más usual asociada con la parálisis facial periférica.

Otros agentes infecciosos incluyen el virus Epstein Barr, el virus de la rubéola, el citomegalovirus, el adenovirus, virus de la influenza $B$, virus coxsackie, la parotiditis, infección rickettsial, y la ehrlichiosis (2).

Se ha visto un aumento del riesgo a sufrir parálisis de Bell asociada con el embarazo, la preeclampsia grave, la diabetes, las infecciones del tracto respiratorio superior y la hipertensión (2). 


\section{MANIFESTACIONES CLÍNICAS}

Las manifestaciones clínicas de la parálisis de Bell se originan por una contractilidad muscular comprometida con daño de las funciones del control neural del nervio facial, que llevan a ocasionar una debilidad muscular progresiva y pérdida de sensibilidad en una hemicara con una afectación nerviosa completa o incompleta (13).

Usualmente, se puede observar en la hemicara afectada una disminución de la fuerza muscular como dificultad para elevar la ceja, sonreír o comer, incapacidad de cerrar el ojo, epifora e impedimento al fruncir los labios además del deterioro del habla por la afectación en la inervación muscular $(5,14)$.

Otros síntomas que se manifiestan son los de afectación sensitiva con dolor alrededor de la mandíbula y detrás del oído, tinnitus, cefalea, pérdida del gusto en los dos tercios anteriores de la lengua e hipersensibilidad al sonido del lado afectado (5).

Frecuentemente, los pacientes solo tienen afectación del séptimo par craneal, sin embargo, se han visto casos de otras neuropatías concomitantes como las son las del trigémino contralateral, glosofaríngeo e hipogloso (2).

Es importante recalcar que la parálisis de Bell se caracteriza por un inicio súbito progresivo de uno a dos días de debilidad facial teniendo una remisión a las dos o tres semanas del inicio del cuadro clínico; en los pacientes con empeoramiento o sin remisión clínica a los cuatro meses se vuelve necesario descartar patología tumoral o denervación $(9,11)$.
Para valorar el compromiso y severidad del nervio facial en la parálisis de Bell se utiliza la Clasificación de House Brackmann aceptada en 1985 por la Academia Americana de Otorrinolaringología y Cirugía de Cabeza y Cuello (TABLA 1) y el Índice de Función del Nervio Facial (IFNF) que consiste en tomar medidas electromiográficas del lado sano y del lado comprometido, en reposo y en contracción $(4,15)$.

\section{DIAGNÓSTICO}

El diagnóstico de la parálisis de Bell es clínico (6). El médico debe incluir una historia clínica completa del paciente sobre la exposición a varios virus (herpes, varicela, $\mathrm{VIH}$, etc.) e investigar el tiempo de inicio de los síntomas (1).

El examen físico valora movimientos faciales con respuesta a órdenes dadas por el explorador, se evalúa la presencia del fenómeno de Bell descrito como una rotación hacia arriba del globo ocular cuando los pacientes intentan cerrar los ojos, presente en el $75 \%$ de la población afectada (1). Adicionalmente, se solicita al paciente elevar la frente, fruncir el ceño y los labios, mostrar los dientes y tensar los tejidos blandos del cuello todo esto buscando la pérdida de la función del músculo orbicular de los párpados, esta situación afecta el manejo adecuado de las lágrimas, así como la pérdida del tono muscular facial, provocando que la ceja junto con la cara media e inferior se inclinen, dando a los pacientes la apariencia de un evento cerebrovascular. Se tiene que realizar una inspección cuidadosa del oído externo, canal 
TABLA 1. Clasificación House Brackmann

\begin{tabular}{|c|c|c|c|c|c|}
\hline \multicolumn{6}{|l|}{ Descripción } \\
\hline Grado & Global & Frente & Ojo & Boca & Sincinesias \\
\hline 1 & \multicolumn{5}{|l|}{ Función facial normal } \\
\hline $\begin{array}{c}2 \\
\text { Disfunción } \\
\text { leve }\end{array}$ & $\begin{array}{l}\text { Debilidad superficial } \\
\text { notable a la } \\
\text { inspección cercana } \\
\text { Al reposo, tono y } \\
\text { simetría normal }\end{array}$ & $\begin{array}{l}\text { Función de } \\
\text { Buena a } \\
\text { moderada }\end{array}$ & $\begin{array}{l}\text { Cierre } \\
\text { completo con } \\
\text { mínimo } \\
\text { esfuerzo }\end{array}$ & $\begin{array}{l}\text { Asimetría } \\
\text { mínima al } \\
\text { movimiento }\end{array}$ & Mínimas \\
\hline $\begin{array}{c}3 \\
\text { Disfunción } \\
\text { leve a } \\
\text { moderada }\end{array}$ & $\begin{array}{l}\text { Paresia generalizada del } \\
\text { rostro pero no } \\
\text { desfigurativa. Asimetría } \\
\text { al reposo y a la actividad }\end{array}$ & $\begin{array}{l}\text { Movimientos } \\
\text { moderados a } \\
\text { ligeros }\end{array}$ & $\begin{array}{l}\text { Cierre } \\
\text { completo con } \\
\text { esfuerzo }\end{array}$ & $\begin{array}{l}\text { Ligera } \\
\text { debilidad con } \\
\text { el máximo } \\
\text { esfuerzo }\end{array}$ & $\begin{array}{l}\text { Existencia de } \\
\text { sincinesias y/o } \\
\text { aumento del tono } \\
\text { de músculos } \\
\text { faciales }\end{array}$ \\
\hline $\begin{array}{c}4 \\
\text { Disfunción } \\
\text { moderada } \\
\text { a severa }\end{array}$ & $\begin{array}{l}\text { Debilidad obvia y/o } \\
\text { asimetría desfigurativa } \mathrm{Al} \\
\text { reposo, asimetría }\end{array}$ & Parestesias & $\begin{array}{l}\text { Cierre } \\
\text { incompleto }\end{array}$ & $\begin{array}{l}\text { Boca; } \\
\text { asimetría al } \\
\text { esfuerzo }\end{array}$ & \\
\hline $\begin{array}{c}5 \\
\text { Disfunción } \\
\text { severa }\end{array}$ & $\begin{array}{l}\text { Movimientos apenas } \\
\text { perceptibles. Asimetría al } \\
\text { reposo }\end{array}$ & Parálisis & $\begin{array}{l}\text { Cierre } \\
\text { incompleto }\end{array}$ & $\begin{array}{l}\text { Movimientos } \\
\text { ligeros }\end{array}$ & \\
\hline $\begin{array}{c}6 \\
\text { Parálisis } \\
\text { total }\end{array}$ & \multicolumn{5}{|l|}{ Sin movimiento } \\
\hline 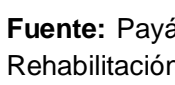 & $\begin{array}{l}\text { Navarro R., Climent I., F } \\
\text { habilitación. 2019. (10) }\end{array}$ & & & & \\
\hline
\end{tabular}

auditivo y la membrana timpánica para identificar vesículas o costras que oriente a una infección por herpes zóster $(2,11)$. La cabeza, la cara y el cuello se inspeccionan para detectar cáncer cutáneo, masas y lesiones masivas dentro de la glándula parótida. Es preciso realizar un examen neurológico minucioso, evaluando todos los pares craneales, con especial atención a la extensión de la debilidad facial buscando la afectación de todas las ramas involucradas (11).

El diagnóstico de la parálisis de Bell se apoya en el descarte de posibles causas neurológicas, otológicas, infecciosas, inflamatorias o neoplásicas (11).

Es importante recalcar que los síntomas asociados de diplopía, disfagia, entumecimiento genuino de la cara o mareos no son típicos de la parálisis de Bell, en cambio son síntomas de bandera roja que nos sugiere hacer sospechar sobre otros diagnósticos (11).

Se puede realizar la obtención de imágenes del cerebro, hueso temporal y glándula parótida con tomografía axial computarizada (TAC) utilizando medio contraste 0 resonancia magnética nuclear (RMN) con gadolinio ya sea si los 
signos físicos son atípicos, se da una progresión de más de tres semanas o si no hay mejoría a los cuatro meses (2).

\section{DIAGNÓSTICO DIFERENCIAL}

El diagnóstico diferencial incluye diversas patologías que en su evolución clínica cursan con debilidad de los músculos faciales (2). Se clasifican en causas congénitas y adquiridas (6).

1. Congénitas (1)

- Malformaciones Congénitas (Síndrome de Moebius)

2. Adquiridas (1)

- Lesiones a nivel de sistema nervioso central

- Tumores

- Eventos cerebrovasculares

- Infecciosas

- Herpes zóster

- HIV

- Otitis media

- Enfermedad de Lyme

- Autoinmunes $(1,2)$

- Síndrome Guillain Barre

- Sarcoidosis

- Síndrome de Sjogren

- Síndrome Melkerson - Rosenthal

- Traumáticas

- Fractura del hueso temporal

- Cirugía

- Barotrauma

\section{TRATAMIENTO}

\section{Manejo en el periodo agudo}

El tratamiento agudo se caracteriza por el uso de un ciclo corto de corticoesteroides y se puede valorar el adicionar medicamentos antivirales por la posibilidad de etiología viral herpes simple en los episodios agudos severos (15). Se recomienda iniciar el ciclo en las primeras 72 horas del inicio de la enfermedad ya que en términos de severidad y recuperación es crucial el tiempo (12).

Se sugiere el corticoesteroide prednisona en dosis de $60 \mathrm{mg}$ a $80 \mathrm{mg}$ por día vía oral a completar una semana; su eficacia en la recuperación es de un $94 \%$ versus placebo con un $81.6 \%(12,15)$. El uso concomitante de antivirales es controversial, se sospecha que disminuye el riesgo de sufrir una recuperación incompleta de la enfermedad; los pacientes que pueden beneficiarse de esta combinación son los que presentan un grado igual o mayor a IV en la clasificación de HouseBrackmann, se utiliza como primera opción valaciclovir en dosis de $1000 \mathrm{mg}$ administrada tres veces al día vía oral por una semana y como segunda opción Aciclovir en dosis de $400 \mathrm{mg}$ cinco veces al día vía oral por diez días $(3,15)$. No se aconseja suministrar el fármaco antiviral como monoterapia por su baja efectividad (7).

Además, en caso de presentar dolor se pueden recetar analgésicos como aspirina, acetaminofén o ibuprofeno (5).

Adicionalmente, se debe implementar la protección ocular con el uso de gotas artificiales en su presentación líquida, gel - pomada cada hora mientras se encuentre despierto y el uso de pomadas con vaselina $o$ aceite mineral durante su sueño, es necesario la prescripción de lentes de protección. Se puede colocar parches en horas de sueño sin adherir la cinta directamente en el párpado por el riesgo de lesión a la córnea (15).En un estudio de baja calidad se aplicó el uso 
de láser de baja potencia mostrando ser una alternativa en casos leves (I-II House Brackmann) por su acción antiinflamatoria y efecto antiedematoso (8). El manejo quirúrgico en la etapa aguda como lo es la descompresión del nervio facial no está recomendado por falta de evidencia en su efectividad y sus múltiples riesgos operatorios (15).

\section{Manejo de seguimiento}

En pacientes con resolución incompleta de sus síntomas o que manifiestan secuelas se puede utilizar la terapia física para la reeducación neuromuscular realizando ejercicios de movimientos faciales como la elevación de cejas, fruncir el ceño y los labios, cerrar los ojos, sonreír e intentar silbar frente a un espejo, además de técnicas de estimulación con las yemas de los dedos realizando percusiones y vibraciones en la zona afectada tres veces al día y/o automasajes por 3 a 5 minutos (9). Existe poca evidencia en la eficacia de la terapia física, aun así, se puede utilizar por su posibilidad de mejorar el pronóstico (7).

En los casos de resolución incompleta el paciente podría requerir toxina botulínica para el manejo de las contracturas musculares y asimetría facial (10).

\section{PRONÓSTICO}

La gravedad de la parálisis de Bell en el paciente define su posible pronóstico. En las lesiones incompletas el $85 \%$ de los pacientes se recuperan en un lapso de tiempo de 22 días siendo un pronóstico favorable, a diferencia de las lesiones completas en donde el porcentaje de recuperación total es del 70\% (15).
Para lograr una evolución satisfactoria de la enfermedad la recuperación espontánea de los síntomas debe de presentarse antes tres semanas del inicio de la enfermedad, sin embargo, el periodo puede incluir hasta dos meses; después de este lapso de tiempo el fracaso en la recuperación funcional es alto (14). El inicio temprano del tratamiento presenta alta probabilidad de recuperación completa (5). Pacientes con grados V o VI de la Clasificación de House Brackmann (TABLA 1) con un inicio de recuperación entre los tres a cuatro meses posterior al inicio clínico tienen una gran probabilidad de recuperación facial motora incompleta. (6). Adicionalmente, el $39 \%$ de los pacientes presentan secuelas de la enfermedad, manifestadas como debilidad muscular, parálisis permanente dolor crónico, sincinesias (contracciones musculares a nivel facial anormales al realizar movimientos voluntarios debido a la reinervación del nervio dañado), asimetría facial, disfunción anatómica e hipertonicidad $(1,7,9,16)$.

Los pacientes con secuelas permanentes desarrollan afectación a nivel emocional y baja autoestima, esto por un impacto directo en su calidad de vida, por lo que es importante brindar soluciones y al mismo tiempo abordaje psicológico (7).

\section{CONCLUSIÓN}

La parálisis de Bell es un síndrome neuromuscular frecuente tanto en hombres como en mujeres con afectación facial motora y sensitiva unilateral y súbita del nervio facial el cual no debe pasar desapercibido por el médico ya que esto puede incidir en el grado de recuperación que tendrá el 
paciente. En la actualidad se desconoce su etiología específica, sin embargo, se sospecha que su principal agente causal es viral por lo que su manejo va dirigido en ese sentido.

El diagnóstico se basa en la sintomatología que presenta el paciente, y un examen físico en el que se evidencie una afección del séptimo par craneal. El uso de elementos complementarios, como, por ejemplo, las imágenes diagnósticas TAC y RMN van dirigidas a descartar patologías con características clínicas similares. Realizar un pronto diagnóstico es fundamental en el momento del abordaje de la parálisis de Bell, el cual debe ser en un lapso menor de 72 horas. Se recomienda utilizar de tratamiento el antiinflamatorio esteroideo prednisona, además se debe valorar su combinación con antivirales junto a la aplicación de protección ocular, buscando prevenir secuelas para obtener un pronóstico favorable para el paciente, en caso de resolución incompleta de los síntomas con presentación de secuelas como hipertonicidad, asimetría facial y sincinesias se propone el uso de terapia física para la reeducación muscular.

\section{REFERENCIAS}

1. Vakharia K, Vakharia K. Bell's Palsy. Facial Plast Surg Clin North AM. 2016; 24(1): 110.http://dx.doi.org/10.1016/j.fsc.2015.08.001

2. Ronthal M. Bell's palsy: Pathogenesis, clinical features, and diagnosis in adults [Internet]. Waltham: Uptodate; 2019 [consultado el 16 marzo 2019]. Disponible en:https://www.uptodate.com/contents/bellspalsy-pathogenesis-clinical-features-and-diagnosis-inadults?search=paralisis\%20de\%20bell\&source=search result\&selectedTitle=2 150\&usage type=default \&display $r a n k=2$

3. Walbaum B, Rada G. ¿Es útil agregar antivirales a los corticoides en la parálisis de Bell en adultos? Medwave. 2015; 15(2): e6226. https://doi:10.5867/medwave.2015.6226

4. Sánchez M, Catacolí J, Echandía C, Zapata J. Evaluación del índice clínico de función del nervio facial en pacientes con parálisis de Bell. Rev Col Med Fis Rehab. 2016; 26(2): 155-161. Disponible en: http://www.revistacmfr.org/index.php/rcmfr/article/view/163

5. Mendoza A, Pereda M, Hernández M, Peña A. Tratamiento con acupuntura en pacientes afectados por parálisis facial periférica. Correo Científico Médico. 2015; 19(3): 441-452. Disponible en: http://scielo.sld.cu/scielo.php?pid=S1560-43812015000300006\&script=sci arttext\&tlng=pt

6. Eviston T, Croxson G, Kennedy P, Hadlock T, Krishnan A. Bell's palsy: aetiology, clinical features and multidisciplinary care. J Neurol Neurosurg Psychiatry. 2015; 86(12): 1356-1361.http://doi:10.1136/jnnp2014-309563

7. Holland J, Bernstein J. Bell's palsy. BMJ Clin Evid. 2014; 2014: 1204.

8. Ferrera T, Hernández M, Castro L, Castro V. Evaluación clínica y funcional de pacientes con parálisis de Bell tratados con láser. MEDISAN. 2015; 19(12): 1459-1465. Disponible en:http://scielo.sld.cu/scielo.php?script=sci arttext\&pid=S1029-30192015001200004

9. Álvarez C, Mora N, González R. Parálisis facial periférica: Enfoque desde la medicina Física y rehabilitación en Costa Rica. Revista Médica de Costa Rica y Centroamérica. 2015; 72(615): $249-255$. Disponible en: http://www.medigraphic.com/cgi-bin/new/resumen.cgi?IDARTICULO=66090

10. Payá A, Navarro R, Climent I, Redondo M. Parálisis facial periférica recurrente y alternante en un servicio de Rehabilitación. Rehabilitación. 2019; 53(1): 60-64.https://doi.org/10.1016/j.rh.2018.06.001 
11. Phan N, Panizza B, Wallwork B. A general practice approach to Bell's palsy. Australian Family Physician. 2016; 45(11): 794-797. Disponible en: https://www.racgp.org.au/afp/2016/november/a-general-practiceapproach-to-bell\%E2\%80\%99s-palsy/

12. Somasundara D, Sullivan F. Management of Bell's palsy. Aust Prescr . 2017; 40(3): 94-97. http://dx.doi.org/ 10.18773/austprescr.2017.030

13. Ríos S. Electroestimulación muscular selectiva utilizada en el tratamiento kinésico de pacientes con parálisis facial periférica aguda y crónica. Rev. Fac. Med. UNNE. 2016; 36(1): 43-47. Disponible en: http://revistas.unne.edu.ar/index.php/rem/article/view/2428

14. Benítez S, Danilla S, Troncoso E, Moya A, Mahn J. Manejo integral de la parálisis facial. Rev. Med. Clin. Conde. 2016; 27(1): 22-28. https://doi.org/10.1016/j.rmclc.2016.01.004

15. Ronthal M. Bell's palsy: Treatment and prognosis in adults [Internet]. Waltham: Uptodate; 2019 [consultado el 17 marzo 2019]. Disponible en: https://www.uptodate.com/contents/bells-palsy-treatmentand-prognosis-in

adults?search=paralisis \%20de\%20bell\&source=search result\&selectedTitle=1 150\&usage type=default \&display rank=1

16. Afrashtehfara C, Afrashtehfara K. Corrección de la sonrisa con toxina botulínica en un paciente con parálisis facial. Rev. Fac. Med. 2015; 58(4): 34-38. Disponible en:http://www.scielo.org.mx/scielo.php?script=sci arttext\&pid=S0026-17422015000400034 